\title{
EXPERIENCES OF HIGHER EDUCATION STUDENTS DURING THE COVID19 CONFINEMENT: ADVANTAGES, DISADVANTAGES AND DIFFERENCES BETWEEN FACE-TO-FACE AND REMOTE LEARNING
}

\author{
Fátima Leal \\ Center for Research in Education and Psychology of University of Évora (PORTUGAL)
}

\begin{abstract}
Corona Virus Disease 2019 led to a state of public health emergency, in so many countries. Preventive measures forced the regime of face-to-face classes, in higher education, to be interrupted and replaced by a system of non-face-to-face classes - Emergency Remote Teaching (ERT). This change has led to the need for adaptation by both teachers and students. Several studies were developed to understand these different perspectives (e.g. [1], [2], [3]). Also, in Portugal, emergency state was declared and universities changed their classes from face-to face to non-face-to-face regime. Researchers like Leal and Chaleta (2020) tried to understand difficulties that students felt when dealing with this new approach class system and found difficulties at cognitive, motivational, interpersonal relationships and personal and academic organization levels [4].

Using a qualitative methodology, this study sought to understand the experiences and perceptions of eight higher education students (age varying from 19 to 23 years old) who suddenly found themselves immersed in this context of remote learning. Interviews were developed and applicated. Content analysis was used, and significant units were categorised, according to Bardin (2008) [5]. Explored topics were students' perception of their experiences, the differences between the two systems, advantages and disadvantages they recognize in the non-face-to-face classroom system.
\end{abstract}

The main results of this study reveal a positive perception, a negative perception, and a change of perspective in the opinion about the classes in a non-face-to-face format. Advantages were found in academic, economic-financial and personal-developmental terms. The pointed-out disadvantages were at a personal, academic and social level.

We conclude that these findings can be very useful in the teaching-learning process. For students in a general way, once they can identify with these verbalizations, they can feel that they are not alone in their academic issues and this can lead to motivating positive changes. For teachers, these results can serve as guidance on some aspects that may have gone better or worse, and accordingly, they may change and adapt their practices to the emergency remote teaching system. On the other hand, higher education institutions can also use these informations about learners experiences to the develop specialized helping programmes to their students (e.g., [6]).

Keywords: Emergency remote teaching, higher education students, experiences, advantages and disadvantages, differences between regimes.

\section{INTRODUCTION}

COVID-19 disease was reported for the first time on 31st December 2019 by Wuhan health authorities, in China. Several countries followed and, in Portugal, the first cases were noted on 4th March 2020. Since then, all over the world, several measures were implemented, involving different sections of society (e.g., health, social, economic, financial, educational). In fact, at the educational level, schools and universities did close impacting on lives of millions of students [7].

In several countries, including Portugal, higher education institutions classrooms were empty, and the face-to-face class regime was substituted by the non-face-to-face class practice. The online approach was amplified, and diverse alternatives were used alternating between synchronous and asynchronous systems (e.g., emails, forums, chats, videoconference systems).

These new practices led to a situation where most of the people started to call to this new regime the "distance learning". However, several professionals but also researchers of conventional "distance learning" discussed and pointed this incorrect utilization of the model [8] 
The dispute is that this sudden change from the face-to-face classes to the non-face-to-face class system, it should not be labeled as "distance education", but as an Emergency Remote Teaching ERT.

This style of education system was already applied in several nations on situations of calamities or natural disasters and it is an emergence alternative to avert the disruption of training and to keep the relationships between learners and educational services [9].

This form of teaching arises to respond to an unexpected demand, and must have a rapid, temporary, and trustworthy solution [10] there is, the ERT should take place immediately, have a provisional character and meet up to minimal requirements [8]. Once the conditions of calamity decrease or dissipate, the teaching scheme ought to go back to its previous state [10].

Leal and Chaleta (2020) refer that the immense challenge of this pandemic state was the need for a quick adaptation to three diverse experiences as the necessity of quarantine where physical and social distance were obligatory; the attempt to get used to this ERT and virtual system in which learners and teachers unexpectedly had to deal with the entire university inside their personal computers and mobiles devices; and the necessity to acquire and apply technological skills crucial to manage diverse tools (e.g. software, computer systems, platforms, applications) [4]

From the students' perspective, the need to adapt to this new situation, and to adopt new ways of study, conducts to the rise of several affective, cognitive, and metacognitive personal and academic experiences.

Several investigations have been developed to understand the effects of this pandemic situation on several fields, but few of them were focused on these aspects.

A study developed by Leal and Chaleta (2020) found that students felt different kinds of difficulties when trading with this non-face-to-face class system (e.g., cognitive, motivational, interpersonal relationships and personal and academic organization levels) [4].

In the present study it is proposed to go further to understand the perceptions of students about these experiences.

\section{METHODOLOGY}

A phenomenographic qualitative methodological perspective was used. This theoretical approach, conceived to respond to educational research issues like thinking and learning, tries to assemble the subjects' experiences and understanding about the several occurrences [11].

This study sought to understand the perceptions of students about the differences of the face-to-face teaching system to the ERT, non-face-to-face teaching system, including advantages and disadvantages.

Eight students from 2nd and 3rd years of undergraduate courses from School of Social Sciences (Psychology, Education and Management Sciences) participated, voluntarily, on this study. All the interviews were applied during the restrict confinement in Portugal. Interviews were conducted online, by videocall system.

Participants signed a term free and informed consent with details about the procedure. Once the sample was very small and this was an exploratory study, a unique group was constituted.

A semi-structured interview guide was used to collect information. Anonymous and confidentiality were respected. The interviews were recorded and totally transcribed. Analysis of the students' speech followed the content analysis technique [5]

\section{RESULTS}

As results we only present some of the most relevant examples of verbalizations to understand the students' answers. 


\subsection{Differences between the face-to-face and the non-face-to-face teaching system}

Some verbalizations from students show us that for them, in some aspects, there are no big differences between the two systems:

"I don't really notice the difference that much ... it's not that different (...) you can keep up..." (S.1)

"I don't see many differences ... for me it's the same" (S.7)

Or even in some other aspects, students report several differences related with the interaction, with the attention and commitment levels, the communication between students and students and teachers.

"Interaction with teachers is completely different" (S.1)

"(...) the level of attention and commitment to that class is different is different in person" (S.6)

"I think the key point is communication... although we are able to communicate through the computer and through a video call, live communication is completely different" (Suj.5)

From the speech of students is possible to find some positive and negative issues related to the nonface-to-face regime.

From an optimistic perspective, two verbalizations indicate that the non-face-to-face regime brought some positive things.

"I think I pay more attention now, perhaps because, I know that this time, the time I have in class is a time when I focus on that class, unlike in-person classes I think I pay more attention now... or at least I feel that I learn more now" (S.7)

"I had my routine in person and now I maintain it and by chance I even have some improvements (...) at least for me it is positive. I know I have to do that and then I prepare as if it were normal [for classes] and I don't feel that frustration" (S.1)

On the other hand, some verbalizations from students led us to think about some negative issues of the non-face-to-face regime: the tiredness of students and teachers, the worst interaction between teachers and students and also, between peers, the perception that they have more academic work to do.

"The biggest differences... first: one difference that I notice a lot is that... everyone is much more tired... both us and the teachers and then it gives us the feeling that, in some classes, teachers even make it a bit late, the beginning of the class" (S.2)

"When we are in class [in person] they [teachers] try to be as interactive as possible in order to answer our questions while here [online system], it gives the idea that each one has a counted time" (S.6)

"In classes [online] I miss that dynamic (...) it is mainly that and to be seeing and listening [in person] to my colleagues" (Suj.3)

"The class is online, the teachers (some, not all) insist that in a certain way, we prepare the class, reading texts or the like before the class... that is... more time... that we have to spend to prepare the class $(. .$.$) It seems that, because it is online, it seems that we have more small tasks to do in addition$ to those that were already established for the assessment at the beginning of the semester" (S.2)

Two other aspects highlighted by students were related with the laziness that comes from the online system and the other hand, the few breaks between two classes.

"On the other hand, I'm even more lazy... because if I used to get up two hours before class started, now I can get up 5 minutes before" (Suj.2)

"If in person we had a break at $11 \mathrm{am}$, we left at 10:45 am of the first class, and we entered at 11:10 am in the next class... not now... we are sitting here, we hang up a video call and start the next one... there is not so much time for rest" (S.2)

Another aspect that was emphasized by students was the assessment moment and tools.

"We did an exam... I think we were very penalized... I think it is like this... I understand the "backwards" that the teacher has because we have access to a lot with a computer in front of us (...) but I think it is not fair having so little time to answer questions" (S.5) 
"Even when presenting works, we have a lot more difficulty communicating because we are not with our group at the side... each one is in his place... I think that makes things more complicated" (S.4)

Some verbalizations of students refer to the idea that when they are participating on online classes, it is important to have the webcam switched on.

"Maybe also [sometimes] we are not $100 \%$ as attentive to classes as we should be... because there are always distractions that we have at home and that we don't have in classes... because in face-toface classes, you must be there... whereas here [online] is something that (...) we are not obliged to have the camera turned on" (S.6)

"sometimes it's a bit more boring because, as we don't show up ... I try to show up as much as possible [activating the camera] (...) because it forces another type of concentration, but when we are not showing up [ on camera] we're more tempted to "oh now I'm going to the cell phone... because nobody is watching" (...) and I try to contradict this a lot so that I don't get distracted... as when I was in person" (S.1)

\subsection{Advantages of the non-face-to-face teaching system}

Regarding the advantages over the non-face-to-face classroom system, 3 main categories emerged: academic, economic-financial and personal.

At the academic level, the resources and the possibility of recording classes were reported.

"If you know how to make good use of the platforms... the elements of study... there is much more information that is provided to you on a virtual level (...) In the classroom regime many teachers pass the slides and you do not stay with them" (S.6)

"(...) We have the possibility to record (...) and that allows us to review the classes later" (S.1)

"And in the classes themselves many times if you don't get a part of the class... if you can't write that part of the class... then it's hard to go back and make it... the teacher starts thinking again to explain it to you... while here you have the advantages of being able to listen to the lessons as many times as necessary" (S.6)

Two verbalizations highlight the greater availability of teachers both to interact with students and to respond to student requests.

"I think that teachers are also a little more open to us because of this..." (S.3)

"As teachers know that they are not available in the classroom, they are much more attentive to emails and concerned with giving feedback to students who send assignments... giving longer deadlines... which turns out to be very good because you have more time, you end up for distributing tasks much better" (S.6)

The creation of discussion forums enables interpersonal interaction but also helps to solidify students' knowledge.

"The forums that teachers create... for debate among us... because that consolidates the subject much more" (S.1)

Interestingly, another advantage emerging in the speech of three students is the fact that, because they are shy people, they feel more comfortable, in this system of virtual classes, to participate in the classes, asking questions and answering the questions of the students. teachers.

"Me in [face-to-face] classes I tend to participate little. It's not because I don't think about what is being said but... I don't know, it's not much part of me, I'm not very talkative and I don't participate much, however, now, it seems that there is a greater pressure for us to effectively participate, to ask questions or until we answer those questions that normally in class can even be a little suspended ... in that sense I think it is a little advantageous because I recognize that at least for me, despite not participating much in the classes, this participation helps to consolidate what is being exposed as to think better about it" (S.2)

"It's easier to talk to teachers and also because the rest of the classmates have their cameras turned off, that is, I don't see their faces or people's reactions, nor do I hear any noise (...) if there was a class and there were noises in the background or so, or laughs, maybe I would think they were laughing at me (...) in that respect it is advantageous for me" (S.5) 
"I'm a little bit shy and I don't have my colleagues looking at me when I'm participating, as we are alone at home, we even managed to be more comfortable" (S.7)

The economic-financial issue emerged at the level of money savings that non-face-to-face classes allow.

"I'm saving a lot of money (...) in transportation (...) at the bar" (S.3)

The last aspect is related to a personal development component, recognizing that this is a learning period for the various players in the educational system and due to the need to develop responsible and self-regulatory strategies in terms of study behaviour.

"This is learning... I mean we are all learning... the teachers, the students... and so what ends up happening... is that you have to adapt to the new education system whereas at the beginning everything could seem very strange as we are getting used to having a different regime and we managed to recognize some advantages" (S.6)

"It requires responsibility on the part of the students... it makes us create this discipline" (S.7)

\subsection{Disadvantages of the non-face-to-face teaching system}

The pointed-out disadvantages were at a personal, academic and social level.

On the personal level, the concentration and the tiredness were the most relevant issues.

"This teaching model takes away my concentration (...) I can't pay the attention I had before" (S.3)

"It's more tiring (...)" (S.5)

"(...) We have no rest time..." (S.2)

"Frustrating and tiring (...) I am here for a number of hours in front of the computer, always sitting in the same position, there are days when I am full of back pain (...)" (S.1).

On the academic level, the excess of work (workload), changes in teaching activities, and also on assessment situations.

"I feel like I have to work a lot more on the computer" (S.1)

"(...) The fact that we have added work (...) we ended up without breaks" (S.2)

"Overwork, what teachers ask for ... ok ... you have a lot more time but you don't have just one chair (...) now you have a lot more things to do" (S.6)

"The practical activities ended up having to be eliminated... due to the context of not being present and it is impossible to carry out these activities" (S.2)

"In tests for example... teachers have no way of controlling whether it is true or not (...) and this is a disadvantage because teachers cannot know which are good students and bad students because they are based on grades that students have ... and it turns out to be a little unfair to those people who have always worked, always worked hard and who may never have copied anything and have lower grades than those students who don't study. " (S.6)

On the social level, the lack of interaction was the most relevant.

"As we don't have that much social interaction now, we have to go to social networks and talk to our friends [but it gets tired... it already gets tired...] even if it is talking to people and it gives me some pleasure, [it is very tiring] (...)" (S.1)

"Not interacting with colleagues... I mean the university is not just about going to classes... it is about having friends, talking to teachers, wanting to do volunteer work... wanting to participate in an investigation and going in person to talk to the teacher for that... I think it goes around a lot... we here online are very limited in several aspects" (S.4)

\section{CONCLUSIONS}

This investigation brings the perspective of students about the non-face-to-face classes system, due to COVID19 constraints. Students were invited to talk about the differences they found in the face-toface and the non-face-to-face teaching system. The differences showed neutral, positive, and negative 
perspectives. Regarding the advantages over the non-face-to-face classroom system, 3 main categories emerged: academic, economic-financial, and personal. The pointed-out disadvantages were at a personal, academic, and social level. These results raise the question that, for some students, the non-face-to-face education system brought disadvantages but, in other situations, it also brought some advantages. Given the fact that the pandemic still exists and that the non-face-to-face education system can be a frequent resource, these results produce novelty and knowledge that reinforce the need to make changes in this education system. Understanding the students' perspective, namely the advantages and disadvantages, can bring clues to change. It would be important to deepen the results of this work with larger samples and with quantitative methodologies that could bring more knowledge about the subject. Future research can explore the affective perspective of students about this non-face-to-face regime.

\section{REFERENCES}

[1] Y.V. Maslov, "Lessons Learned from Emergency Remote Teaching during the COVID-19 Pandemic", 2020

[2] R. Eder, "The Remoteness of Remote Learning: A Policy Lesson from COVID19. Journal of Interdisciplinary Studies in Education, vol.9, no. 1, pp. 168-171, 2020.

[3] A. Jr. Alvarez, "The phenomenon of learning at a distance through emergency remote teaching amidst the pandemic crisis". Asian Journal of Distance Education, vol.15, no. 1, pp.144-153, 2020.

[4] F. Leal and E. Chaleta Face-to-face and remote learning during the confinement due to Covid19: the experience of higher education students. 2020. 3th International Conference on Research in Teaching and Education. RTECONF. 15 ${ }^{\text {th }}-17^{\text {th }}$ December, 2020.

[5] L. Bardin, Análise de conteúdo. Lisboa, Portugal: Edições 70, 2008.

[6] E. Chaleta, F. Leal and M. Campos, "Online study - um programa de suporte ao estudo e aprendizagem de estudantes de ensino superior. $10^{a}$ Conferência Forges. O ensino superior na era digital nos países e regiões de língua portuguesa: desafios e propostas. 18-20 Novembro, 2020.

[7] F.J.O. Araújo, L.S.A. Lima, P.I.M. Cidade, C.B. Nobre, and M.L.R. Neto, "Impact Of Sars-Cov-2 And Its Reverberation In Global Higher Education And Mental Health" Psychiatry Research, vol. 288, 112977. ISSN 0165-1781, 2020

[8] N. Pedro, "Webinário Ensino Online em Situação de Emergência: Analisar o Passado, Planear o Futuro". Available in: https://www.youtube.com/watch?v=CD4_c64cLFE\&t=332s. 2020

[9] C. Hodges, S. Moore, B. Lockee, T. Trust, and A. Bond, "The diference between emergency remote teaching and online learning." Educause. Rev. https://er.educause.edu/articles/2020/3/ the-diference-between-emergency-remote-teachingand-onlin e-learning. Accessed 23 Mar 2020

[10] A.O. Mohmmed, B.A. Khidhir, A. Nazeer, and V.J. Vijayan, "Emergency remote teaching during Coronavirus pandemic: the current trend and future directive at Middle East College Oman" Innovative Infrastructure Solutions, vol. 5, no. 3, pp1, 2020.

[11] F. Marton, "Phenomenography—A Research Approach to Investigating Different Understandings of Reality", Journal of Thought, vol. 21, no.3, pp. 28-49, 1986. 